modification of standards for significant hazards. As well, social attitudes change and society generally becomes more risk-averse over time. An alternative approach is 'continuous quality improvement' (CQI), which is an on-going process for the optimisation of risk, efficiency of operations, and consumption of resources. The 'Deming Cycle' (Plan $\rightarrow \mathrm{Do} \rightarrow$ Study $\rightarrow$ Act $\rightarrow$ [repeat]), for example, is the standard management approach for quality assurance in the private sector. CQI has advantages over fixed standard setting in improving the quality of the environment and worker health and fits better with good management practices. The theoretical disadvantages may be business concern over an ever shifting target for compliance and the opportunity cost of making improvements when performance is already sufficient. However, in practice, CQI has shown such great benefit in improving the operations of enterprises from small business to large corporations that it is standard procedure and typically results in large unanticipated gains beyond quality, in efficient operations, lower cost, and reduced risk. This approach is rarely used in occupational health protection but it has been adopted as 'Best Available Control Technology' in other settings. In the United States, the mandated periodic review of ambient air quality standards by the EPA and of high-priority chemicals under the Lautenberg Chemical Safety Act are broadly compatible with CQI. The approach is also one means of effectively operationalizing the Precautionary Principle. It is suggested that CQI should be reconsidered as an alternative regulatory approach and adopted as a fundamental approach to risk management.

\section{WOMEN HEALTH AND WORK}

${ }^{1}$ Ravindra Kumar*, ${ }^{2}$ Pragati Patil, ${ }^{3}$ Shriniket Mishra, ${ }^{4}$ Anoop Singh. ${ }^{1}$ Hero MotoCorp Ltd, Neemrana, India; ${ }^{2}$ Indian Army, India; ${ }^{3}$ Chief Medical Officer, Hero MotoCorp Ltd; ${ }^{4}$ Assistant Professor, Dr SN Medical College Jodhpur

\subsection{6/oemed-2018-ICOHabstracts.443}

Introduction India, Women working on shop floor is new concept for Automobile industries. women taking up tools to partake in manufacturing of two-wheelers, hitherto a male bastion. As the call for women empowerment gets louder, Automobile two-wheeler manufacturers are responding with an aim to create a culture where women can stand shoulder to shoulder with their male counterparts to contribute to the growth of the company. Occupational health Centre is concerned about their health, a cross-sectional scientific study conducted in an automobile industry to assess Body Mass Index with an aim to make healthy work pattern suitable to their physiology.

Method Study was conducted on 27 randomly selected unmarried women work team member in age group of 19-24 years of frame assembly section in an automobile industry. Job was working on assembly line of two wheeler of automobile manufacturing industry. Parts pick from conveyor tray and to mounting on frame body of two-wheeler. Measure the weight and height and then calculate the BMI of the team member were computed at the time of joining and after 6 month of staring work, general clinical check-up including heart rate, and oxygen saturation and BP monitoring before and after the 6 month interval of work schedule.

Results Women working on shop floor mean age 21.5 years, mean weight $44.40 \mathrm{~kg}$ and mean height $161.66 \mathrm{~cm}$ and mean BMI 18.28 taking balance and with 8 hours shift duty, leave as per prorota basis, 48 hours work in one week. Review periodical medical examination after 6 month found mean height 161.66 and mean weight $50.30 \mathrm{~kg}$ and mean BMI 20.88 .

Conclusion This is first surveillance of women health status in automobile industry in India under occupational health physician. Taking balance diet with structured work pattern with appropriate work atmosphere result in improved average BMI.

\section{THE STRESS CHECK PROGRAM: AN EVALUATION OF THE FIRST-YEAR IMPLEMENTATION OF THE NEW NATIONAL WORKPLACE MENTAL HEALTH PROGRAM IN JAPAN}

${ }^{1} \mathrm{~N}$ Kawakami ${ }^{*},{ }^{1} \mathrm{~K}$ Imamura, ${ }^{1} \mathrm{Y}$ Asai, ${ }^{1} \mathrm{~K}$ Watanabe, ${ }^{2} \mathrm{~A}$ Tsutsumi, ${ }^{2} \mathrm{~A}$ Shimazu, ${ }^{2} \mathrm{~A}$ Inoue, ${ }^{3} \mathrm{H}$ Hiro, ${ }^{4} \mathrm{Y}$ Odagiri, ${ }^{5} \mathrm{~T}$ Yoshikawa, ${ }^{6} \mathrm{E}$ Yoshikawa. ${ }^{1}$ Graduate School of Medicine, The University of Tokyo, Tokyo, Japan; ${ }^{2}$ Kitasato University, Sagamihara, Japan; ${ }^{3}$ University of Occupational and Environmental Health, Kitakyushu, Japan; ${ }^{4}$ Tokyo Medical University, Tokyo, Japan; ${ }^{5}$ National Institute of Occupational Safety and Health, Kawasaki, Japan; ${ }^{6}$ Japanese Red Cross College of Nursing, Tokyo, Japan

\subsection{6/oemed-2018-ICOHabstracts.444}

Introduction The Stress Check Program mandates workplaces with 50 or more employees in Japan to provide their employees with an opportunity for a stress survey (the stress check), followed by a doctor interview for employees with high stress. Improvement of psychosocial work environment based on analysis of the stress check data is also recommended. The program went into its first year round between December 2015 and November 2016. The current paper overviews the implementation and effectiveness of the program in the first year.

Methods We reviewed reports from prefectural (local) labour bureaus wherever available. A prospective study of workplaces $(n=217)$ randomly selected was conducted to know the implementation and related costs. A prospective study of an internet sample of full-time workers $(n=2500)$ was also conducted to know the effects of the program for improving psychological distress. A workshop was held to listen to occupational health professionals and human resource personnel who engaged in running the program at their workplaces.

Result Prefectural labour bureaus reported that about $80 \%$ of workplaces implemented the program; the participation rate to the stress check was high (74\% to 94\%); only a small proportion of employees with high stress took the doctor interview. A similar pattern was found in the workplace cohort. In the cohort of workers, psychological distress was improved in a group that participated in the stress check and experienced work environment improvement significantly better than in a control group who did neither. Occupational health professionals had some difficulties in implementing the new program in the first year, while they planned to improve their practice in the second year.

Discussion The Stress Check Program was well implemented in the first year, while the beneficial effect of the program may be limited to those who experienced work environment improvement following the stress check.

\section{AN ERGONOMIST IN A CONTINUOUS IMPROVEMENT TEAM. LESSONS LEARNED FROM THE AVIATION MAINTENANCE INDUSTRY}

J Carmo*, M Lima. ,2UCS- Integrated Healthcare SA, TAP Portugal Group, Lisbon, Portugal

10.1136/oemed-2018-ICOHabstracts.445 
Introduction The field of ergonomics and the field of quality have a history as two separate disciplines. Both fields are relatively young and are largely of an applied nature. The dominating paradigms have undergone changes in recent years. On the other hand, Health and Safety has its own place, centred in the improvement of working conditions. At TAP PORTUGAL, these three domains are organised in such a way that the ergonomics interventions are embedded in the Occupational Health and Safety department, at UCS, the healthcare provider for all the TAP group companies. One of these companies is the maintenance unit, a MRO, TAP Maintenance and Engineering that plans each year, two Continuous Improvement Weeks and recently the ergonomist has been invited to collaborate.

Methods The ergonomist was invited to participate in three Continuous Improvement Weeks, part of a multidisciplinary team (4 elements) with workers and engineers. The projects were: 'Redesign of a Coffee Machines Test Bench'; 'Brake parts transportation cart' and 'Maintenance aircraft lighting'. The ergonomic analysis methodologies were applied as well as the tools of continuous improvement, requiring an effort of adaptation between the professional different points of view.

Results Both Quality and Ergonomics tools were applied and the teams produced recommendations regarding performance and health and safety concerns.

Discussion The introduction of an ergonomist in the team of continuous improvement improves the final result of the process since the importance of the human factor is determinant for the success of the projects. In order to participate in these teams the ergonomist needs to master the Quality analysis tools, to have the time to carry out the work activity analysis and to obtain information (especially KPI) of both ergonomics and health and safety domains.

\section{WORKING CONDITIONS IN GERMAN HOSPITALS- PREVENTION FOR YOUNG PHYSICIANS AND NURSING STAFF IN GERMANY}

Peter Koch, Albert Nienhaus. University Medical Center Hamburg Eppendorf, Hamburg, Germany

\subsection{6/oemed-2018-ICOHabstracts.446}

Background The implementation of the Diagnose Related Groups-System in Germany has led to substantial work intensification over the years. Due to these structural changes a high dissatisfaction with work and early exit from work especially for nursing staff has been observed in studies. Also physicians working in hospitals complain about their working conditions characterised by not documented overtime, personnel shortage, missing breaks and a perceived lower care quality. With respect to these working conditions, the demographic development of patients and health care workers, young health care workers today are the future potential of the capacity of German hospitals. The following research investigates the working conditions of young physicians and nurses in a joint context. The aim of this study is to detect specific needs for improvement with respect to the collaboration of the two job groups.
Methods The statutory accident insurance of health care workers in Germany (BGW) has the statutory obligation to prevent work- related diseases. In collaboration with two unions and several medical and nursing societies the BGW is performing a large representative survey in September 2017. The study population are young physicians and nurses ( $\leq 35$ years) working in German hospitals. Access to the field will be attained by the different databases of the union and society members. A randomised sample of 8000 young health care workers will get access to the web-based survey via email. The questionnaire will assess different work-related aspects with the Copenhagen Psychosocial Questionnaire (COPSQ). Other psychosocial factors will be assessed with the Effort-RewardImbalance-Questionnaire (ERI). Especially aspects of collaboration of the two job groups and specific needs for improvement that are asked in the questionnaire, will give essential information to build up new strategies to enhance work satisfaction of young health care workers.

\section{DEVELOPMENT OF OCCUPATIONAL HEALTH SERVICES PRACTICES STANDARDS IN ACCREDITING PRIMARY CARE UNITS IN THAILAND}

O Untimanon*, K Boonmeephong, A Promrat, T Saipang, K Sukanun. Bureau of Occupational and Environmental Diseases, Department of Disease Control, Ministry of Public Health, Thailand

\subsection{6/oemed-2018-ICOHabstracts.447}

Introduction A total of 9770 primary care units (PCUs) in Thailand have provided many health care services, such as the improvement of nutrition of young children, immunisation, investigations of communicable diseases and non- communicable diseases. Integration of occupational health services (OHS) in the PCUs is very important because high risk workers who work in the communities can access such services easily. Implementation strategy can start with quality control program that integrating with holistic healthcare delivered by PCUs therefore the OHS practices standards were developed to be a guideline for PCUs to carry out OHS interventions.

Methods The OHS practices standards were developed using Delphi technique. Thirty Delphi panellists from related agencies were asked to answer the 3 rounds of questionnaire. Consensuses were formed and the actual outcomes could be presented among the panellists' response. Such standards were summarised and figured. The criteria were developed following the items of such standards. Draft standards and criteria were used to evaluate the pilot PCUs and they were revised to be more clearly following the suggestion to suit the real situation.

Results Such standards were divided into four components including:

- organisational set up, human resources, plans, evaluation and occupational health network collaboration,

- OHS for health worker of PCUs,

- pro-active occupational health services for community workers,

- in-house occupational health services and

- integration of environmental health services. 